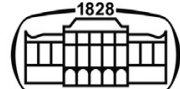

AKADÉMIAI KIADÓ

\title{
Influence of imperfections in the buckling resistance of steel beam-columns under fire
}

\author{
Samer Nemer* ${ }^{*}$ and Ferenc Papp
}

\section{Pollack Periodica • An International Journal for Engineering and Information Sciences}

16 (2021) 2, 1-6

DOI:

10.1556/606.2021.00303

(c) 2021 The Author(s)

\section{ORIGINAL RESEARCH} PAPER

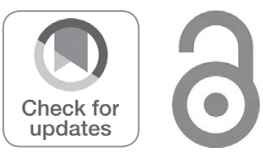

Department of Structural and Geotechnical Engineering, Faculty of Architecture, Civil Engineering and Transport Sciences, Széchenyi István University, Egyetem tér 1, 9026 Győr, Hungary

Received: November 21, 2020 • Revised manuscript received: January 17, 2021 • Accepted: January 29, 2021 Published online: April 21, 2021

\section{ABSTRACT}

This paper presents an investigation on the influence of structural imperfections on the ultimate load capacity of steel welded beam-columns with class 4 cross-section under elevated temperatures. This is done by considering different amplitudes for the global and local (plate) imperfections, and different residual stresses distributions available in the literature. To this purpose, a geometrically and materially non-linear finite element model using Abaqus software has been used to determine the buckling resistance of a steel welded beam-column at elevated temperatures, using the material properties of EN1993-1-2. The imperfection sensitivity of beam-columns is reported: the influences of the amplitudes of the geometric imperfection and the patterns of the residual stress on the load capacity are compared.

\section{KEYWORDS}

steel, fire design, finite element analysis, imperfections, residual stress

\section{INTRODUCTION}

Welded I-steel members are widely used in the construction of buildings and structures due to their high functionality. The real structural steel members are not perfectly straight. Throughout the manufacturing process (e.g., thermal cutting processes, which involve intense local heating and rapid cooling and different types of welding [1]), the fabrication of the sections results in global and local (plate) geometrical imperfections (e.g., out-ofstraightness), and mechanical (material) imperfections (e.g., residual stresses). Besides, due to high width-to-thickness ratio of I-section steel members, local buckling occurs [2]. These imperfections considerably affect the behavior of steel members and reduce their buckling resistance [3]. For normal temperatures cases, Annex C of EN 1993-1-5 [4] introduces guidance on the use of Finite Element (FE) methods. It states that both initial global and local (plate) imperfections should be included in the FE-model in a way that one type of imperfection should be chosen as a leading imperfection, and the accompanying imperfections may be reduced to $70 \%$. Moreover, geometric imperfections may be based on the shape of the first buckling modes, and $80 \%$ of the geometric fabrication tolerances are recommended. Regarding residual stresses, the Eurocode states that structural imperfections in terms of residual stresses may be represented by a stress pattern from the fabrication process with amplitudes equivalent the mean (expected) values. However, there is no possibility to consider different patterns of welded residual stresses, despite their considerable influence [5, 6]. The residual stresses for welded sections are different from hot-rolled sections mainly because of the difference in the manufacturing processes. While residual stresses have a negligible effect on I-shaped hot-rolled Class 4 sections, it was proved to have a considerable effect on the ultimate load-carrying capacity of the welded cross-sections [5]. Moreover, different residual stress distributions lead to a different capacity reduction on welded crosssections [3]. 
EN1993-1-2 [7] in an informative annex E adapts a number of simple application rules for designing steel members at elevated temperatures. However, the shape of the cross-section and the pattern of residual stresses are completely ignored at elevated temperature. Accurate representation of the magnitude and distribution of the geometrical imperfections and residual stresses in steel cross-section is significant for the assessment of the buckling behavior of steel members and for the development of accurate design rules.

In this paper, the influence of these imperfections on the ultimate load capacity of beam-columns with class-4 I-shaped cross-section at elevated temperatures is investigated. Different geometrical imperfection amplitudes and residual stress patterns found in the literature have been implemented in Abaqus numerical model as initial structural imperfections.

\subsection{Review of the previous work}

For ambient temperature, a growing body of literature has examined the influence of geometrical imperfections [8], and residual stress experimentally [9], and numerically [10, 11]. A recent research was carried out by Couto et al. [3], who investigated the effect of material and geometrical imperfections on the capacity of welded slender I-shaped beams. It was stated that considering Taras [12] or European Convention for Constructional Steelwork (ECCS) [13] residual stress patterns results in maximum reduction in the load-carrying capacity (the worst-scenario). In addition to that, a value of $b / 100$ was recommended for the maximum effect of the local imperfection (where $b$ is the width of the flange or the depth of the web depending on the most displaced node).

Some previous researchers investigated numerically the influence of imperfections on the buckling behavior of steel members under fire situation. It was noted by Kaitila [14] that the increase of local imperfections' magnitude leads to a relatively straightforward reduction in the initial stiffness of the member; while the magnitude of global imperfection has a bigger effect on the ultimate load of the member. Moreover, the author proposed $L / 500$ and web height $h / 200$ as suitable values for global and local imperfections, respectively (where $L$ is the overall span of the beam). Vila Real et al. [15] investigated the effects of the residual stresses on the lateral-torsional buckling of steel beams at elevated temperatures. It was concluded that the influence of the residual stresses in the lateral-torsional buckling of beams is bigger for intermediate slenderness, as is the case at room temperature. Moreover, the influence of the residual stresses decreases with increasing temperature. Later, Vila Real et al. [16] investigated the influence of three parameters on the lateral-torsional buckling of steel I-beams under fire conditions: the steel grade (S235-S355-S460), the pattern of residual stresses (rolled and welded sections), and the ratio ( $h /$ $b$ ) between the depth $h$ and the width $b$ of the cross section. The authors claimed that the influence of the investigated parameters when considered separately is limited. However, the combination of these factors has a more significant effect. The magnitude and distribution of residual stress for welded high strength Q460 and mild steel Q235 steel Hshaped sections were investigated experimentally at both room and elevated temperatures [17]. The maximum value of residual stress reduced significantly from $50 \%$ of the yield strength before fire exposure, to $12 \%$ of yield strength after fire exposure. Thus, it was stated that the maximum value of residual stress varies at elevated temperatures, and should be put into account in fire resistance design of high strength steel structures. However, this conclusion has been limited to the case of high strength steel, and no similar evidence for carbon steel. Besides, the ECCS residual stress pattern is commonly used in most numerical studies which investigate buckling behavior of steel members at elevated temperatures $[6,15,16]$. Kervalishvil [18] studied the influence of residual stresses on the stability of steel columns at elevated temperatures. Results for models ignoring and accounting for residual stresses were compared for different steel grades, various slenderness values, temperatures and section types. It was concluded that, for low slenderness values for strong axis buckling of hot-rolled $\mathrm{H}$-sections and hollow section members, the effect of residual stresses is negligible. On the other hand, the residual stresses have more effect on strong axis buckling out of this range and weak axis buckling of $\mathrm{H}$ sections, and disregarding them brings about reduction of accuracy. Independent of the residual stresses the design code prediction of the buckling capacity for certain lower slenderness range at fire temperatures appear on the unconservative side compared to the numerical model. The review of the publications above indicates that most previous researches in this field have been limited to the influence of geometric and material imperfections on the stability design of steel members at normal temperatures, and the information on the influence of the imperfections in fire conditions is not sufficient. Although the influence of geometrical imperfections amplitudes and residual stress are diverse and should be accurately considered to avoid oversimplification as proved by many researchers, a deeper research on the effect of structural imperfections on buckling strength at elevated temperatures should be provided.

\section{SENSITIVITY ANALYSIS METHODS}

\subsection{Case study}

A simply supported I-shaped welded steel member comprised of three steel plates, namely top and bottom flanges and web, with overall length of $6,000 \mathrm{~mm}$ is considered for this study. It is made of steel grade S235. Figure 1 shows the studied member and the applied loads (axial load: $N=95.8 \mathrm{kN}$, bending moment: $M=13.10 \mathrm{kN} /$ $\mathrm{m})$.

The geometry of the welded cross section is shown in Table 1, along with the temperatures considered and the residual stresses patterns and the initial imperfection amplitudes that are compared in this study, being $L$ the overall 


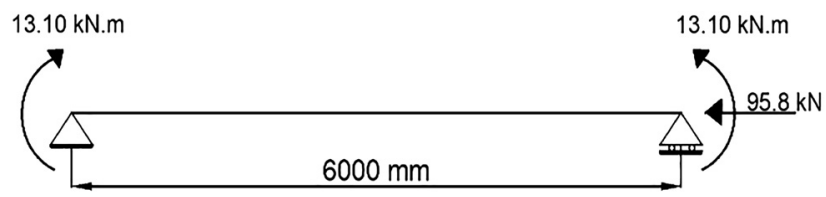

Fig. 1. Details of the beam-column with the applied loads used in this study

span of the member, and $b$ is the flange width or web height depending for which the maximum displacement occurs in the corresponding local buckling mode. The residual stresses patterns were introduced into the Abaqus model as "initial conditions: type $=$ stress" [19]. The same residual stress patterns were compared for beams with slender I-shaped welded sections at room temperature in [3].

\subsection{Material model}

The S235 steel grade was considered in this study. For linear buckling analysis, linear elastic material law with Young's modulus $E$ equals to $2.1 \times 10^{5} \mathrm{MPa}$ is used. The Poisson's ratio is set to 0.3 .

For the non-linear analysis under normal temperatures an elastic-plastic stress-strain relationship material law defined by a yield strength of $235 \mathrm{MPa}$, an ultimate strength of $360 \mathrm{MPa}$, a Young's modulus of $210 \mathrm{GPa}$, and a Poisson ratio of 0.3 .

At elevated temperatures, the reduction factors for the stress-strain relationship of carbon steel at elevated temperatures from EN1993-1-2 [7] were used as it is shown (Table 2).

For non-linear analysis at elevated temperatures, Abaqus requires the full stress-strain response to correctly represent the structural behavior. The stress-strain relationships for steel S235 were taken using the equations provided by EN1993-1-2 [7]. The influence of thermal expansion has not been considered.

\subsection{Numerical model}

2.3.1. Model description. Buckling capacities of steel beamcolumn members were calculated by finite element method, using four-node shell elements S4R (with reduced integration to avoid shear and membrane locking) in software package Abaqus. Shell elements have the ability to recognize the local buckling of thin plates in members of Class 4 cross section.
Table 2. Reduction factors at $\theta$ relative to the value of $f_{y}$ and $E_{a}$ at 20 ${ }^{\circ} \mathrm{C}[7]$

\begin{tabular}{lcccc}
\hline Steel & $k_{y, \theta}=$ & $k_{p, \theta}=$ & $k_{E, \theta}=$ & $k_{0.2 p, \theta}=$ \\
temperature & $f_{y, \theta} / f_{y}$ & $f_{p, \theta} / f_{y}$ & $E_{a, \theta} / E_{a}$ & $f_{0.2 p, \theta} / f_{y}$ \\
\hline $20{ }^{\circ} \mathrm{C}$ & 1 & 1 & 1 & 1 \\
$400{ }^{\circ} \mathrm{C}$ & 1 & 0.42 & 0.7 & 0.65 \\
$500{ }^{\circ} \mathrm{C}$ & 0.78 & 0.36 & 0.6 & 0.53 \\
\hline
\end{tabular}

The mesh size was determined to be 16 elements in the flange, 16 elements in the web depth and with size of $20 \mathrm{~mm}$ across the member length as shown in Fig. 2. The maximum aspect ratio of the elements was equal to 4 .

The loads are modeled by applying distributed forces (by means of nodal forces) on the flanges and on the web of the loaded end using the modified method (also known as arc length method) available in the Abaqus library. Boundary conditions imposed on the member were appropriate to simply supported beam-column with free axial expansion.

2.3.2. Elastic linear buckling analyses. The imperfection of the finite element model is included by first performing a Linear Buckling Analysis (LBA) on the perfect prismatic beam-column model with given boundary conditions under given compression force and bending moment, in order to obtain the buckling modes of the member.

Both first (lowest) global and first (lowest) local buckling mode shapes are shown in Fig. 3, respectively. As mentioned before, superposition of overall buckling mode as well as local buckling mode is achieved for accurate finite element analysis, and particularly in this study for the purpose of comparison.

2.3.3. Nonlinear load-displacement analyses. In the following Geometrically and Materially Nonlinear Analysis with

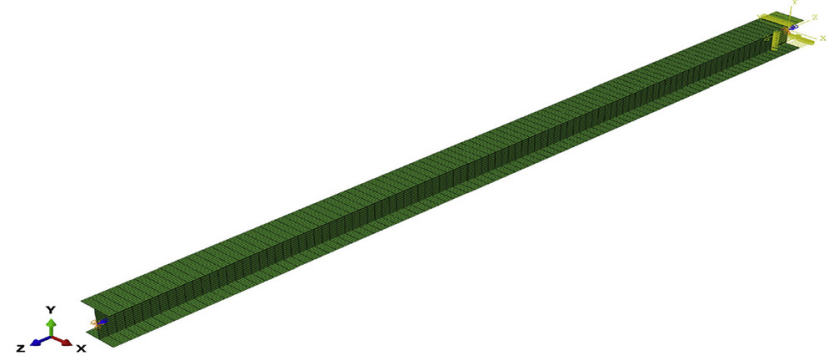

Fig. 2. Numerical model used in this study

Table 1. Properties of the cross-section

\begin{tabular}{lccccc}
\hline Geometry & & Temperatures & Residual stress patterns & Global imperfection & Local imperfection \\
\hline$h$ & $300(\mathrm{~mm})$ & $20{ }^{\circ} \mathrm{C}$ & Taras [12] & $L / 2,000$ & $b / 100$ \\
$b$ & $240(\mathrm{~mm})$ & $400{ }^{\circ} \mathrm{C}$ & ECCS [13] & $L / 1,000$ & $b / 200$ \\
$t_{w}$ & $4(\mathrm{~mm})$ & $500{ }^{\circ} \mathrm{C}$ & Barth and White [20] & $L / 800$ & \\
$t_{f}$ & $6(\mathrm{~mm})$ & & Chacón [21] & $L / 600$ & \\
$A$ & $4,032\left(\mathrm{~mm}^{2}\right)$ & & Best-fit Prawel [22] & $L / 400$ & \\
\hline
\end{tabular}




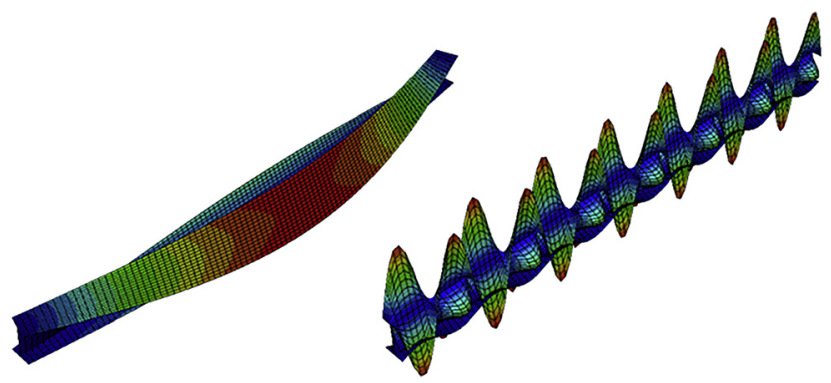

a)

b)

Fig. 3. a) First global and b) local buckling modes

Imperfections (GMNIA), the imperfections were established by importing the normalized displacements of the first global and the first local buckling modes, multiplying these by the initial imperfection amplitudes and updating the nodal coordinates of the model by adding the established nodal imperfections.

\section{RESULTS}

\subsection{Sensitivity to initial global and local imperfections}

The combinations of the initial global and local imperfections considered are presented in Table 3. The ECCS residual stress pattern [15] is considered in the numerical simulations. The results show the direct correlation between the amplitude of the initial imperfections and the buckling resistance of the studied member. The bigger the imperfection values, the smaller the buckling capacity. The load capacity difference between the case when initial global imperfection is equal to $L / 2,000$ and the case when it equals to $L / 400$ (with fixed local imperfection b/100) is: (118.924 $106.953) / 106.953 \approx 11 \%$ at $500{ }^{\circ} \mathrm{C}$, while it is equal to $9.9 \%$ at room temperature. On the other hand, the amplitude of initial local imperfection, especially when accompanied by a relatively big initial global imperfection amplitude (e.g., L/400), has a smaller effect on the load capacity of the member.

Figure 4 shows the different buckling resistance at $500{ }^{\circ} \mathrm{C}$ for all cases that have fixed initial local imperfection $(b / 200)$ and different initial global imperfection amplitudes. It can be seen that the initial global imperfection value affects not only the ultimate strength but also the initial stiffness. When increasing the initial global imperfection with fixed initial local imperfection amplitude, the ultimate strength and initial stiffness decrease significantly.

Figure 5 shows the different buckling capacities at $500{ }^{\circ} \mathrm{C}$ for cases with fixed initial global imperfection and two different local imperfection amplitudes. It shows clearly that the initial local imperfection has no influence on the initial stiffness of the member.

It is worthy to mention that axial force and bending moment increase proportionally, so that only the axial forcedisplacement relationship is presented.
Table 3. Results of initial global and local imperfections sensitivity analysis

\begin{tabular}{|c|c|c|c|c|}
\hline $\begin{array}{l}\text { Model } \\
\text { ID }\end{array}$ & $\begin{array}{c}\text { Global } \\
\text { imperfection }\end{array}$ & $\begin{array}{c}\text { Local } \\
\text { imperfection }\end{array}$ & $\begin{array}{c}\text { Temperature } \\
\left({ }^{\circ} \mathrm{C}\right)\end{array}$ & $\begin{array}{c}\text { Load } \\
\text { capacity } \\
(\mathrm{kN})\end{array}$ \\
\hline \multirow[t]{3}{*}{ NL 1} & $L / 2,000$ & $b / 100$ & 0 & 185.042 \\
\hline & & & 400 & 134.251 \\
\hline & & & 500 & 118.924 \\
\hline \multirow[t]{3}{*}{ NL 2} & $L / 2,000$ & $b / 200$ & 0 & 188.204 \\
\hline & & & 400 & 136.847 \\
\hline & & & 500 & 121.696 \\
\hline \multirow[t]{3}{*}{ NL 3} & $L / 1,000$ & $b / 100$ & 0 & 179.9 \\
\hline & & & 400 & 130.404 \\
\hline & & & 500 & 115.273 \\
\hline \multirow[t]{3}{*}{ NL 4} & $L / 1,000$ & $b / 200$ & 0 & 183.341 \\
\hline & & & 400 & 132.880 \\
\hline & & & 500 & 117.429 \\
\hline \multirow[t]{3}{*}{ NL 5} & $L / 800$ & $b / 100$ & 0 & 177.667 \\
\hline & & & 400 & 128.745 \\
\hline & & & 500 & 113.625 \\
\hline \multirow[t]{3}{*}{ NL 6} & $L / 800$ & $b / 200$ & 0 & 181.143 \\
\hline & & & 400 & 131.107 \\
\hline & & & 500 & 115.460 \\
\hline \multirow[t]{3}{*}{ NL 7} & $L / 600$ & $b / 100$ & 0 & 174.259 \\
\hline & & & 400 & 126.258 \\
\hline & & & 500 & 111.113 \\
\hline \multirow[t]{3}{*}{ NL 8} & $L / 600$ & $b / 200$ & 0 & 177.786 \\
\hline & & & 400 & 128.545 \\
\hline & & & 500 & 112.449 \\
\hline \multirow[t]{3}{*}{ NL 9} & $L / 400$ & $b / 100$ & 0 & 168.31 \\
\hline & & & 400 & 122.082 \\
\hline & & & 500 & 106.953 \\
\hline \multirow[t]{3}{*}{ NL 10} & $L / 400$ & $b / 200$ & 0 & 171.76 \\
\hline & & & 400 & 124.582 \\
\hline & & & 500 & 106.662 \\
\hline
\end{tabular}

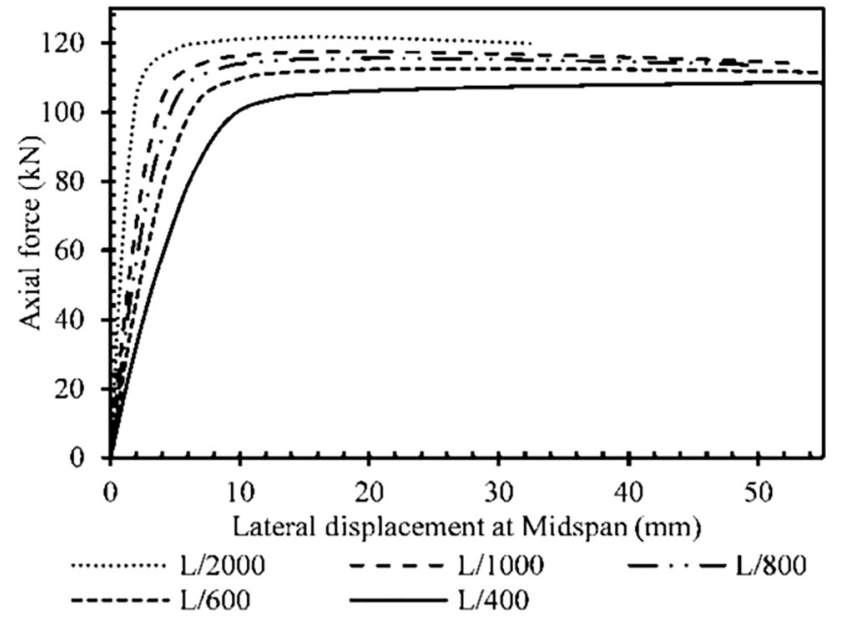

Fig. 4. Load capacity of the studied member at $500{ }^{\circ} \mathrm{C}$ with initial local imperfection $b / 200$ and different initial global imperfection values

\subsection{Sensitivity to residual stresses}

The results presented in Fig. 6 shows the influence of the residual stress on the ultimate strength of the beam-column 


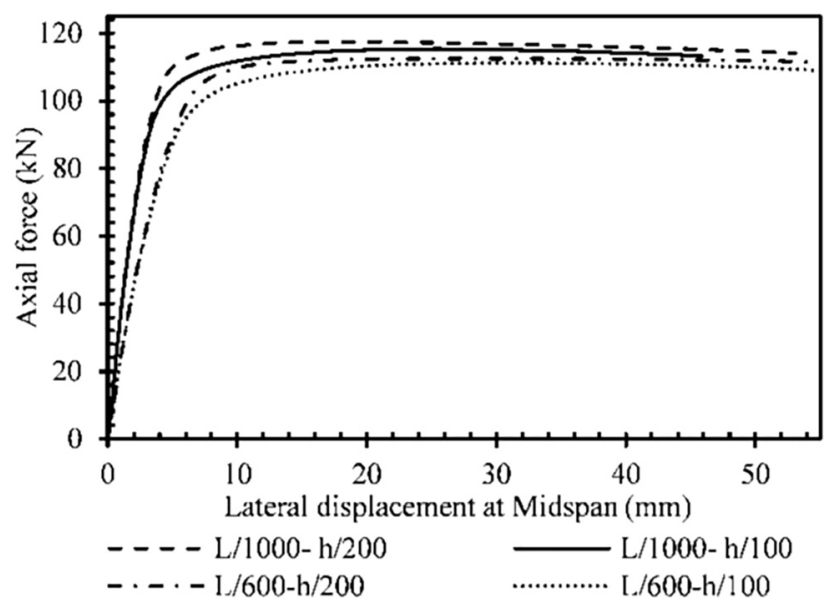

Fig. 5. Load capacity of the studied member at $500{ }^{\circ} \mathrm{C}$ with fixed global imperfection and two different initial local imperfection values

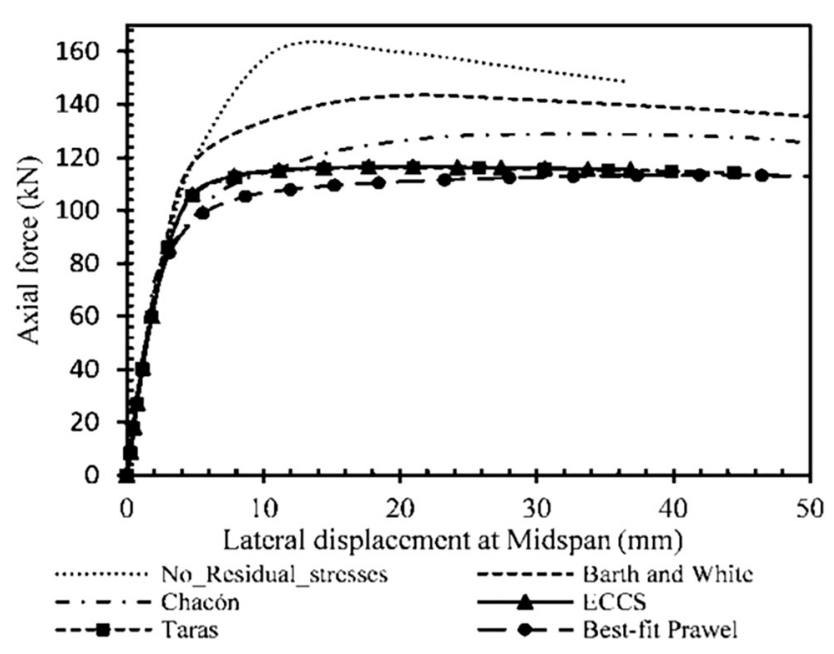

Fig. 6. Influence of different residual stresses distributions at $500{ }^{\circ} \mathrm{C}$

at $500{ }^{\circ} \mathrm{C}$ (with initial global and local imperfections equals to $80 \%$ of $L / 750$ for the global mode and $(70-80 \% \cdot b / 100)$ for the local mode in accordance with recommendations given in the Annex C of EN1993-1-5). It can be seen that considering Taras and ECCS residual stress patterns at 500 ${ }^{\circ} \mathrm{C}$ results in almost the same response. Moreover, "Best-fit Prawel" pattern gives the worst scenario (most conservative). On the other hand, "Barth and white" has the least influence.

Table 4 shows the influence of the residual stress on the ultimate strength of the beam-columns at room temperature, $400{ }^{\circ} \mathrm{C}$, and $500{ }^{\circ} \mathrm{C}$. At room temperature, ECCS residual stress pattern gives the lowest ultimate strength and it

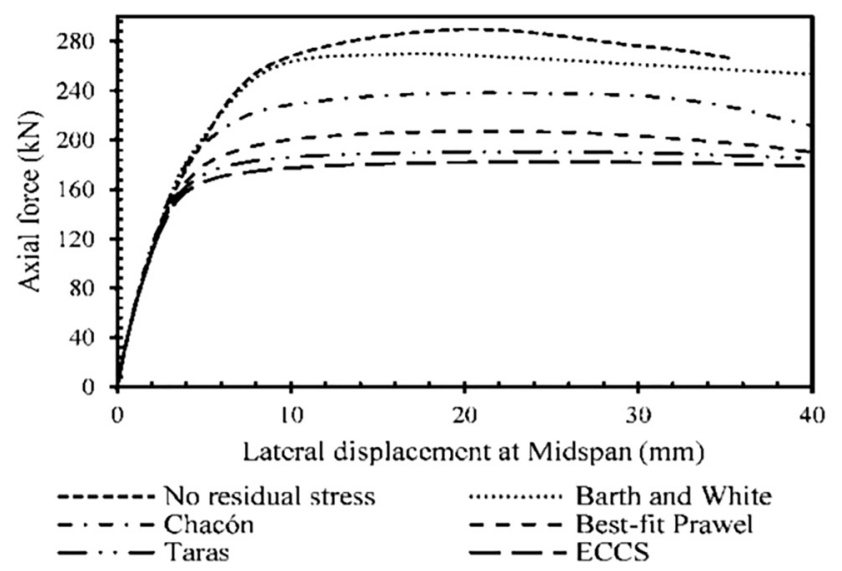

Fig. 7. Influence of different residual stresses distributions at ambient temperature

represents the most conservative scenario. However, at 400 ${ }^{\circ} \mathrm{C}$, Taras and ECCS residual stress patterns give almost the same ultimate strength, and for higher temperatures, considering "Best-fit Prawel" pattern results in the most conservative result (the least buckling resistance). Moreover, it can be seen that the effect of residual stress at $500{ }^{\circ} \mathrm{C}$ is about $13 \%$ less than its effect at ambient temperature which is illustrated in Fig. 7.

\section{CONCLUSION}

In this paper, an investigation on the influence of imperfections, namely, the initial geometrical imperfections (both global and local), and residual stress, upon the buckling load capacity of steel members subjected to axial force and bending moment at elevated temperatures is presented. It was found from the imperfection sensitivity analysis that initial global imperfection value affects not only the buckling resistance but also the initial stiffness of the studied member. The increase of the amplitude of the initial global imperfection resulted in a considerable decrease in the ultimate strength and initial stiffness. It can be seen that the effect of initial global imperfection on the investigated beam-column is slightly bigger at elevated temperatures. Although the initial local imperfection has lower effect on the ultimate strength and no influence on the initial stiffness, the results reaffirmed the importance of considering both imperfections for the finite element modeling. The residual stress sensitivity analysis showed that the buckling resistance of the beam-column is slightly less sensitive to the residual stresses when the temperature increases. However, the influence is

Table 4. Results of initial global and local imperfections sensitivity analysis

\begin{tabular}{lcccccc}
\hline Temperature $\left({ }^{\circ} \mathrm{C}\right)$ & Barth and White $(\mathrm{kN})$ & Taras $(\mathrm{kN})$ & Best-fit Prawel $(\mathrm{kN})$ & Chacón $(\mathrm{kN})$ & ECCS $(\mathrm{kN})$ & NO residual stress $(\mathrm{kN})$ \\
\hline 500 & 143.28 & 116.22 & 113.34 & 128.88 & 116.58 & 160.81 \\
400 & 169.38 & 132.62 & 135.14 & 153.16 & 132.03 & 187.57 \\
0 & 269.49 & 190.32 & 207.21 & 238.29 & 182.24 & 289.48 \\
\hline
\end{tabular}


significant and should be taken into account. Finally, from the analysis of the influence of different residual stress patterns at different temperatures, it was also observed that, at room temperature, ECCS residual stress pattern has the largest effect on the buckling resistance. However, at $500{ }^{\circ} \mathrm{C}$ considering Taras or ECCS residual stress patterns results in almost the same response, and Best-fit Prawel pattern has the biggest influence (the most conservative case). On the other hand, "Barth and white" pattern has the least influence under all temperatures.

\section{REFERENCES}

[1] Š. Klarić, Ž. Rosandić, and A. Milinović, "Examination of welding parameters' influence on stud arc welding process", Pollack Period., vol. 6, no. 3, pp. 45-52, 2011.

[2] K. Jármai and M. Petrik, "Optimization and comparison of different standards for compressed welded box columns", Pollack Period., vol. 15, no. 1, pp. 3-14, 2020.

[3] C. Couto and P. Vila-Real, "Numerical investigation on the influence of imperfections in the lateral-torsional buckling of beams with slender I-shaped welded sections", Thin-Walled Struct., vol. 145, Paper no. 106429, 2019.

[4] EN 1993-1-5, Eurocode 3, Design of steel structures, Part 1-5: Plated structural elements, CEN, Brussels, 2006.

[5] C. Couto and P. Vila-Real, "Numerical investigation on the influence of imperfections in the local buckling of thin-walled Ishaped sections", Thin-Walled Struct., vol. 135, pp. 89-108, 2019.

[6] A. Kervalishvili and I. Talvik, "Influence of residual stress on the stability of steel columns at elevated temperatures", J. Civil Eng. Manage., vol. 23, no. 2, pp. 292-299, 2017.

[7] EN 1993-1-2, Eurocode 3, Design of steel structures, Part 1-2: General rules - structural fire design, CEN, Brussels, 2005.

[8] N. Boissonnade and H. Somja, "Influence of imperfections in FEM Modeling of lateral torsional buckling", in Proceedings of the Annual Stability Conference, Texas, USA, April 18-21, 2012, 2012, pp. 1-15.

[9] B. Yang, G. Xiong, S. Nie, M. Elchalakani, and Q. Zhu, "Experimental and model investigation on residual stresses in Q460GJ thick-walled I-shaped sections", J. Construct. Steel Res., vol. 145, pp. 489-503, 2018.
[10] C. Rolando, M. Serrat, and R. Esther, "The influence of structural imperfections on the resistance of plate girders to patch loading", Thin-Walled Struct., vol. 53. pp. 15-25, 2012.

[11] B. W. Schafer and T. Peköz, "Computational modeling of cold formed steel: Characterizing geometric imperfections and residual stresses”, J. Constructional Steel Res., vol. 47, pp. 193-210, 1998.

[12] A. Taras, "Contribution to the development of consistent stability design rules for steel members", Doctoral Thesis, Technical University Graz, 2010.

[13] R. Greiner, G. Salzgeber, and R. Ofner, "New lateral torsional buckling curves $\chi \mathrm{LT}$ - Numerical simulations and design formulae", European Convention for Constructional Steelwork Technical Committee, Technical report, Report no. TC-8-2000014, 2000.

[14] O. Kaitila, "Imperfection sensitivity analysis of lipped channel columns at high temperatures", J. Construct. Steel Res., vol. 58, pp. 333-351, 2002.

[15] P. M. M. Vila-Real, R. Cazeli, L. S. da Silva, A. Santiago, and P. Piloto, "The effect of residual stresses in the lateral-torsional buckling of steel I-beams at elevated temperature", J. Constructional Steel Res., vol. 60, pp. 783-793, 2004.

[16] P. M. M. Vila-Real, N. Lopes, L. S. da Silva, and J. M. Franssen, "Parametric analysis of the lateral-torsional buckling resistance of steel beams in case of fire," Fire Saf. J., vol. 42, no. 6-7, pp. 416424, 2007.

[17] W. Y. Wang, G. Q. Li, and Y. Ge, "Residual stress study on welded section of high strength Q460 steel after fire exposure", Adv. Steel Construct., vol. 11, pp. 150-164, 2015.

[18] A. Kervalishvili and I. Talvik, "Influence of residual stress on the stability of steel columns at elevated temperatures", J. Civil Eng. Manage., vol. 23, no. 2, pp. 292-299, 2017.

[19] Abaqus/Standard, Version 5.8, User's manual, Hibbitt, Karlsson and Sorensen, Inc, USA, 1998.

[20] K. E. Barth and D. W. White, "Finite element evaluation of pier moment-rotation characteristics in continuous-span steel I girders", Eng. Struct., vol. 20, pp. 761-778, 1998.

[21] R. Chacón, M. Serrat, and E. Real, "The influence of structural imperfections on the resistance of plate girders to patch loading", Thin-Walled Struct., vol. 53, pp. 15-25, 2012.

[22] Y. Kim, "Behavior and design of metal building frames using general prismatic and web-tapered steel I-section members", $\mathrm{PhD}$ Thesis, Georgia Institute of Technology, 2010. 